\title{
On the construction of regions of stability
}

\author{
Luciano Miguel Lugo ${ }^{1}$, Juan Eduardo Nápoles Valdés ${ }^{1,2}$, Samuel Iván Noya ${ }^{2}$ \\ ${ }^{1}$ Facultad de Ciencias Exactas, UNNE, Av. Libertad 5540 (3400), Corrientes, ARGENTINA \\ ${ }^{2}$ Facultad Regional Resistencia, UTN, French 414 (3500), Resistencia, ARGENTINA
}

\section{Email address:}

1mlmb@yahoo.com.ar (L. M. Lugo),jnapoles@exa.unne.edu.ar(J. E. Nápoles Valdés), samuelivannoya@gmail.com (S. I. Noya)〉

\section{To cite this article:}

Luciano Miguel Lugo, Juan Eduardo Nápoles Valdés, Samuel Iván Noya. On the Construction of Regions of Stability. Pure and Applied Mathematics Journal. Vol. 3, No. 4, 2014, pp. 87-91. doi: 10.11648/j.pamj.20140304.12

\begin{abstract}
In this paper we built a stability region around the origin for the Liénard equation (4) to ensure stability and boundedness of solutions of this equation, without making use of the classical Second Method of Lyapunov. We compare our result with some others proposed by different authors.
\end{abstract}

Keywords: Lyapunov, Trajectories, Asymptotic Equilibrium

\section{Introduction}

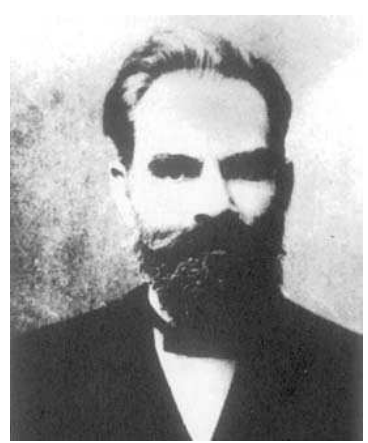

The term "stability" originates in Mechanic to characterize the equilibrium of a rigid body. So, the equilibrium is called stable if the body returns to its original position, having been "disturbed" by being moved slightly from its position of rest. If the body after a slight displacement tends toward a new position its equilibrium is called unstable.

The Second Method of Lyapunov has been established as the most general method to study the stability of equilibrium positions of systems described by differential, differences or functional equations (or systems). This method was found in classical memory of Alexander Mijaílovich Lyapunov ${ }^{1}$, published in Russian in 1892 , translated into French in 1907 (reprinted 40 years later ${ }^{2}$ )

\footnotetext{
${ }^{1}$ Born on June 6, 1857 in Yaroslavl, Russia and died on November 3, 1918 in Odessa, Russia.

${ }^{2}$ Lyapunov (1949).
}

and in English many years later ${ }^{3}$. In this work a key role is played by the calls Lyapunov functions (functions of energy from the physical point of view).

Lyapunov's second method also determines the criteria for asymptotic stability. In addition to giving us these criteria, it gives us the way of estimating region of asymptotic stability. Asymptotic stability is one of the major areas of the qualitative theory of dynamical systems and is of paramount importance in many applications of the theory in almost all fields where dynamical effects play a great role.

In the analysis of region of asymptotic stability properties of invariant objects, it is very useful to employ what is now called Lyapunov's second method. It is an important method to determine region of asymptotic stability. This method relies on the observation that asymptotic stability is very well linked to the existence of a Lyapunov's function, that is, a proper, nonnegative function, vanishing only on an invariant region and decreasing along those trajectories of the system not evolving in the invariant region. Lyapunov proved that the existence of a Lyapunov's function guarantees asymptotic stability and, for linear time-invariant systems, also showed the converse statement that asymptotic stability implies the existence of a Lyapunov's function in the region of stability.

An excellent source for the study of this method (also called direct method because this method allows us to determine the stability and asymptotic stability of a system without explicitly integrating the nonlinear differential

\footnotetext{
${ }^{3}$ Lyapunov (1962) and Lyapunov (1992), in this last is included a biography by Smirnov and an extensive bibliography of Lyapunov's work.
} 
equation) is the renamed text Yoshizawa of the sixty ${ }^{4}$. In the qualitative study of a nonlinear system, whether autonomous

$$
\mathrm{x}^{\prime}=\mathrm{F}(\mathrm{x}) ; \mathrm{x} \in \mathrm{R}^{\mathrm{n}}
$$

or non-autonomous

$$
x^{\prime}=F(x, t) ; x \in R^{n},
$$

suppose that $\mathrm{F}(\mathrm{t}, \mathrm{x})$ is continuous in $(\mathrm{t}, \mathrm{x})$ on $\mathrm{IxD}$, where $\mathrm{D}$ is a connected open set in $\mathrm{R}^{\mathrm{n}}$, I denote the interval $0 \leq \mathrm{t}<\infty$ and $\mathrm{R}^{\mathrm{n}}$ denote the Euclidean $\mathrm{n}$-space with the norm $\|\mathrm{x}\|$. In the qualitative theory some of the most studied qualitative properties are stability, asymptotic stability and the boundedness (also called continuability) ${ }^{5}$ :

The solution $\mathrm{x}=\mathrm{x}^{*}(\mathrm{t})$ of (2) is stable in the Lyapunov sense, if for any $\varepsilon>0$ and any $\mathrm{t}_{0} \in \mathrm{I}$, there exists $\delta\left(\mathrm{t}_{0}, \in\right)>0$ such that if

$$
\left\|x *\left(t_{0}\right)-x\left(t_{0}\right)\right\|<\delta \text { then }\|x *(t)-x(t)\|<\varepsilon, \forall \mathrm{t} \geq \mathrm{t} 0 .
$$

The solution $\mathrm{x}=\mathrm{x} *(\mathrm{t})$ of (2) is asymptotically stable in the Lyapunov sense, if $\mathrm{x}^{*}(\mathrm{t})$ and if there exists a $\delta_{0}\left(\mathrm{t}_{0}\right)>0$ such that if

$$
\left\|x *\left(t_{0}\right)-x\left(t_{0}\right)\right\|<\delta_{0}\left(t_{0}\right) \text { then }\|x *(t)-x(t)\| \rightarrow 0 \text { as } \mathrm{t} \rightarrow \infty \text {. }
$$

Remark1. In many physical situations, the origin may not be asymptotic stable for all possible initial value $\left(\mathrm{t}_{0}, \mathrm{x}_{0}\right)$ but only for initial value contained in some region around the origin, such a region is called the region of asymptotic stability and the value of $\delta$ allows to define a neighborhood of $\mathrm{x}^{*}\left(\mathrm{t}_{0}\right)$, commonly called base attraction. If this neighborhood coincides with the whole space, then it is said to be asymptotically stable in the global sense.

A solution $\mathrm{x}=\mathrm{x} *(\mathrm{t})$ of $(2)$ is bounded, if there exists a $\beta>0$ such that $\left\|x^{*}(t)\right\|<\beta$ for all $\mathrm{t} \geq \mathrm{t}_{0}$, where $\beta$ may depend on each solution. In other words if and only if for all $\mathrm{T}>\mathrm{t}_{0}$ we have $\lim _{t \rightarrow T^{-}} x(t)<\infty$.

One way to ensure that these properties are fulfilled for all solutions of the system, is to propose a bounded region $\Omega$ around equilibrium point in which remain all those solutions beginning on $\Omega$, ie, if $\mathrm{x}\left(\mathrm{t}_{0}\right) \in \Omega$, then $\mathrm{x}(\mathrm{t}) \in \Omega$, for all $\mathrm{t}>\mathrm{t}_{0}$. Throughout the work, and for convenience, we take $\mathrm{t}_{0}=0$.

In this paper we consider the Liénard equation:

$$
x^{\prime \prime}+f(x) x^{\prime}+g(x)=0 ; x \in R, t \geq 0
$$

where $\mathrm{f}$ is a continuous function, $\mathrm{g}$ is a derivable function and the following assumptions are fulfilled:

a) $\mathrm{f}(\mathrm{x})>0$, if $\mathrm{x} \neq 0$,

b) $x g(x)>0$, if $x \neq 0$.

\footnotetext{
${ }^{4}$ Yoshizawa (1966).

${ }^{5}$ Yoshizawa (1966), p.27, p.28 and p.36
}

Let $\mathrm{F}(\mathrm{x})=\int_{0}^{x} f(u) d u$ and $\mathrm{y}=\mathrm{x}^{\prime}+\mathrm{F}(\mathrm{x})$, then (3) can written as a system:

$$
\left\{\begin{array}{l}
x^{\prime}=y-F(x) \\
y^{\prime}=-g(x)
\end{array}\right.
$$

This system has the origin as a single equilibrium point, so the properties will be referred to the trivial solution $\mathrm{x}(\mathrm{t})=\mathrm{y}(\mathrm{t})=0$.

In our work we will need the following basic results ${ }^{6}$.

Theorem A. Let $\Omega$ be a bounded neighborhood of the origin and let $\Omega^{\mathrm{c}}$ be its complement. Assume that $\mathrm{W}(\mathrm{x})$ is a scalar function with continuous first partials in $\Omega^{\mathrm{c}}$ and satisfying:

1. $\mathrm{W}(\mathrm{x})>0, \forall \mathrm{x} \in \Omega^{\mathrm{c}}$,

2. $\mathrm{W}^{\prime}(\mathrm{x}) \leq 0, \forall \mathrm{x} \in \Omega^{\mathrm{c}}$,

3. $\mathrm{W}(\mathrm{x}) \rightarrow \infty$ as || $\mathrm{x}|| \rightarrow \infty$.

Then each solution of (1) is bounded for all $\mathrm{t} \geq 0$.

Theorem B. Let $\mathrm{V}(\mathrm{x})$ be a scalar function with continuous first parcials satisfying:

1. $\mathrm{V}(\mathrm{x})>0, \forall \mathrm{x} \neq 0$,

2. $\mathrm{V}^{\prime}(\mathrm{x}) \leq 0, \forall \mathrm{x}$,

3. $\mathrm{V}(\mathrm{x}) \rightarrow \infty$ as || $\mathrm{x}|| \rightarrow \infty$.

If $\mathrm{V}^{\prime}$ is not identically zero along any solution other than the origin, then the system (1) is completely stable ${ }^{7}$.

The main difficulty in using Theorem B often is that one can construct a Lyapunov function satisfying the three requirements. Hence it is much easier to study the boundedness of the solutions as a separate problem, from which arises the need to build appropriate regions where we can ensure the boundedness.

Building the stability region of a given equation is another way to study the problem of convergence, as $t$ tends to infinity, of all solutions of this equation. This problem is of a paramount relevance in the qualitative theory.

The purpose of this note is to construct a new stability region for equation (3), using a different approach of earlier results and without making uses of common conditions. First we summarize know results, we present by illustration the proof of first, and later we present our results.

\section{Preliminary Results}

While there are some previous results in the fifties, the first result of this nature was obtained by LaSalle in 1960 , when he showed that all solutions of (4) are stable and bounded using an appropriate bounded region.

\subsection{Region $1^{8}$}

Theorem 1. Under assumptions a) and b) if we have

\footnotetext{
${ }^{6} \mathrm{Cf}$. Theorems 4 and 5 of LaSalle (1960).

${ }^{7}$ Continuable for us.

${ }^{8}$ LaSalle (1960).
} 


$$
|F(x)|=\left|\int_{0}^{x} f(u) d u\right| \rightarrow+\infty \text { as }|\mathbf{X}| \rightarrow \infty
$$

then, all solutions of (2) are stable and bounded.

Proof. Let $(\mathrm{x}(\mathrm{t}), \mathrm{y}(\mathrm{t}))$ be a solution of (4), and let 1 and a positive real numbers such that $(\mathrm{x}(0), \mathrm{y}(0)) \Omega$, where $\Omega$ is the region:

$$
\Omega=\left\{(x, y) \in R^{2} / V(x, y)=\frac{1}{2} y^{2}+G(x)<l \wedge(y+F(x))^{2}<a\right\}
$$

Where $\mathrm{V}(\mathrm{x}, \mathrm{y})$ is the Lyapunov Function $\mathrm{V}(\mathrm{x}, \mathrm{y})=\frac{y^{2}}{2}+G(x)$ with $G(x)=\int_{0}^{x} g(s) d s$. However, since it may not be true that $\mathrm{G}(\mathrm{x}) \rightarrow \infty$ as $|\mathrm{x}| \rightarrow \infty$, we can conclude only that every solution bounded for all $\mathrm{t} \geq 0$ approaches the origin as $\mathrm{t} \rightarrow \infty$. Thus, to establish complete stability, we need to show that all solutions are bounded for $t \geq 0$. To do this, we consider the region $\Omega$ (see figure of the Region 1).

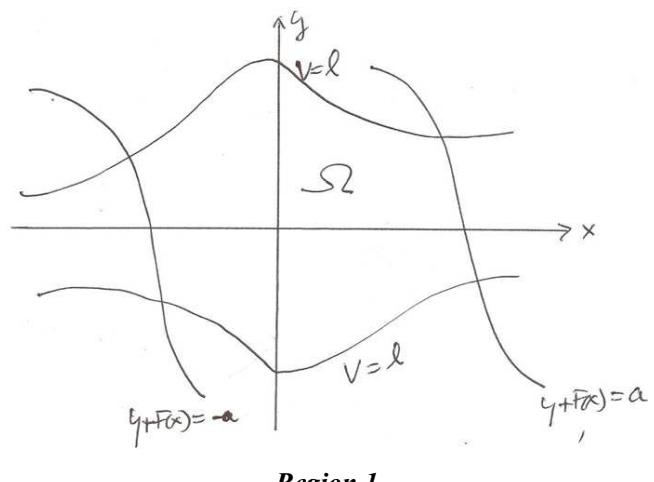

For any 1 and a, $\Omega$ is a bounded region ${ }^{9}$. Let $(\mathrm{x}(\mathrm{t}), \mathrm{y}(\mathrm{t})$ be any solution, and select 1 and a so large that the solution starts in $\Omega$. Then the solution cannot leave $\Omega$ without crossing the boundary of $\Omega$. It must cross either $\mathrm{V}=1$ or $\mathrm{y}+\mathrm{F}(\mathrm{x})=\mathrm{a}$, or $\mathrm{y}+\mathrm{F}(\mathrm{x})=-\mathrm{a}$. We can select a suficiently large that the part of $y+F(x)=a$ which is the boundary of $\Omega$ correspond to $\mathrm{x}>0$ and the part of $\mathrm{y}+\mathrm{F}(\mathrm{x})=-\mathrm{a}$ corresponds to $\mathrm{x}<0$.

The derivative of $\mathrm{V}(\mathrm{x}, \mathrm{y})$ along the system (4) is:

$$
\begin{aligned}
& V^{\prime}{ }_{(4)}=y y^{\prime}+g(x) x^{\prime}= \\
& -y g(x)+g(x)(y-F(x))=-g(x) F(x) \leq 0, \forall(x, y) \in R^{2},
\end{aligned}
$$

From (5) we have that a solution starting inside $\Omega$ cannot cross $\mathrm{V}=1$.

Now in the rest of boundary of $\Omega$ we have

$$
\begin{aligned}
\frac{d}{d t}(y+F(x))^{2} & =2(y+F(x))\left(y^{\prime}+f(x) x^{\prime}\right) \\
& =2(y+F(x))(-g(x)+f(x)(y-F(x))) \\
& =2(-g(x)(y+F(x))+f(x)(y-F(x))(y+F(x))) \\
& =-2 a|g(x)|<0
\end{aligned}
$$

\footnotetext{
${ }^{9}$ Cf. Miller and Michel (1982).
}

Because $g(x)(y+F(x))>0$. Hence, $(\mathrm{x}(\mathrm{t}), \mathrm{y}(\mathrm{t}))$ cannot leave $\Omega$, and every solution is bounded for $\mathrm{t} \geq 0$. Thus, under somewhat different conditions we have again shown that Liénard's equation is completely stable.

Remark 2. If we consider (3) under an external force $\mathrm{x}^{\prime \prime}+\mathrm{f}(\mathrm{x}) \mathrm{x}^{\prime}+\mathrm{g}(\mathrm{x})=\mathrm{p}(\mathrm{t})$ with $\mathrm{p}$ a continuous function and of class $\mathrm{L}^{1}[0,+\infty)$, this result still valid and the proof is practically the same ${ }^{10}$. It's funny, comparing the similarity of the paper of LaSalle and Hasan and $\mathrm{Zhu}$, and dates of both, how in the second job is not mentioned first, suggesting a lack thereof.

\subsection{Region $2^{11}$}

Theorem 2. Under condition b) we suppose that

$$
\exists \mathrm{a}>0 / 0<|\mathrm{x}|<\mathrm{a} \Rightarrow \mathrm{xF}(\mathrm{x})>0 .
$$

Then all solution of (4) are stable and bounded.

Remark 3. It is clear that the above condition is more general than a).

In the proof we consider the same Lyapunov's function $V(x, y)=\frac{1}{2} y^{2}+G(x)$. And we take $\Omega$ as the infinite band:

$$
\Omega=\left\{(x, y) \in R^{2} /-a \leq x \leq a\right\} .
$$

In this region we have:

$$
V^{\prime}{ }_{(4)}(x, y)=y y^{\prime}+g(x) x^{\prime}=-y g(x)+g(x)(y-F(x))=-g(x) F(x) \leq 0 \text {. }
$$

So we have $\mathrm{V}^{\prime}{ }_{(4)}(\mathrm{x}, \mathrm{y}) \leq 0$ in any subset of $\Omega$. Let $\mathrm{C}_{\lambda}$ be the region definite by $C_{\lambda}=\left\{(x, y) \in R^{2} / V(x, y) \leq \lambda\right\}$, with $\lambda$ is a positive real number such that $C_{\lambda} \subset \Omega$. It is clear that the better value of $\lambda$ is the lowest value between $G(a)$ and $G(-a)$.

Again we have the no positivity of $\mathrm{V}^{\prime}\left({ }_{4}\right)(\mathrm{x}, \mathrm{y})$ we guarantee the boundedness and stability of solutions starting in $\mathrm{C}_{\lambda}$ (Region 2 in the figure bellow).

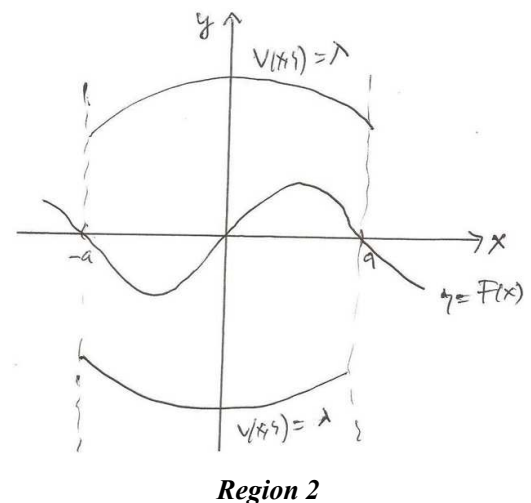

\subsection{Our Region ${ }^{12}$}

While the construction of the stability region can be at

\footnotetext{
${ }^{10}$ See Hasan and Zhu (2007).

${ }^{11}$ Cf. Yadeta (2013).

${ }^{12}$ A preliminary version of this result was presented at the Annual Meeting of the UMA last year. See Lugo, Nápoles and Noya (2013).
} 
times by the Second Method of Lyapunov, we shall disregard it in the results presented below.

We next give a stability region allowing us to obtain sufficient conditions for the boundedness and stability of solutions of the system (4), and consequently for the equation (3).

Theorem 3. If in addition to conditions a) and b) we have

$$
\begin{gathered}
\mathrm{f} \in \mathrm{F}_{\lambda, \mathrm{g}}(\mathrm{R})=\{\mathrm{f} \in \mathrm{C}(\mathrm{R}) / \mathrm{f}(\mathrm{x})-\lambda \mathrm{g}(\mathrm{x})>0 \\
\mathrm{x}<0\},
\end{gathered}
$$

then all solutions of (4) are stable and bounded.

Proof. Let $(x(t), y(t))$ be a solution of (4) with initial value $(\mathrm{x}(0), \mathrm{y}(0))=\left(\mathrm{x}_{0}, \mathrm{y}_{0}\right)$, and we take the region:

$$
\Omega_{k}^{G}=\left\{(x, y) \in R^{2} / \alpha \leq x \leq \beta ;|y| \leq-k G(x)+\frac{1}{k}\right\} .
$$

Where $\mathrm{k}$ is a positive real number satisfying the equation $y_{0}=-k G\left(x_{0}\right)+\frac{1}{k}$; and $\alpha$ and $\beta$ are the solutions of equation $G(x)=\frac{1}{k^{2}}$ (note that proposed equation to find the value of $\mathrm{k}$ is equivalent to asking that the solution "start" on the boundary of the region).

Calculating the slopes of the boundary we have:

$$
-k g(x)=\frac{d y}{d x}=-\frac{g(x)}{x^{\prime}}, \text { from here we have that } x^{\prime}=\frac{1}{k} \text { if } \mathrm{y}>0
$$

$$
k g(x)=\frac{d y}{d x}=-\frac{g(x)}{x^{\prime}}, \text { where } x^{\prime}=-\frac{1}{k} \text { if } \mathrm{y}<0 .
$$

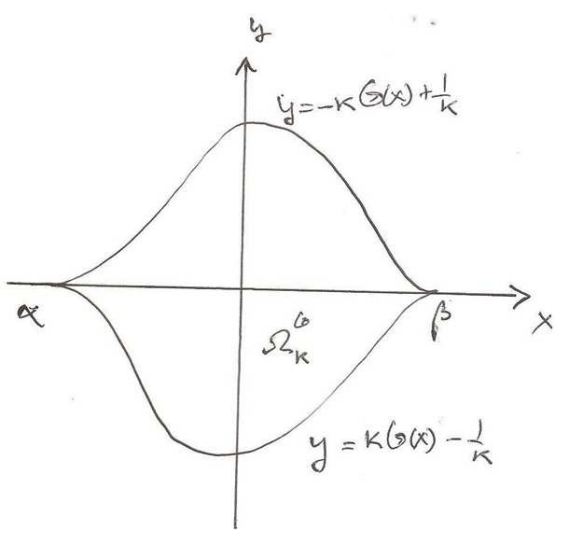

Our Region

So, if we have $x^{\prime}=\frac{1}{k} \quad$ if $\mathrm{y}>0$ and $x^{\prime}=-\frac{1}{k} \quad$ if $\mathrm{y}<0$, the trajectories that begin at the boundary of this region, "fall" into the same, which ensures the stability and continuability of the solution considered (see Our Region in the previous figure).

\section{Final Remarks}

- $\quad$ Region 1 has 4 points of intersection in the given boundary, and those points can not speak of derived.

- The Region 2 does not have that problem, but as the value of $\mathrm{a}$ is fixed in advance, the proposed region $\mathrm{C}_{\lambda}$ can not cover all solutions of the equation.

- $\quad$ Region 3 has the advantage that it was not needed to define a Lyapunov function (so, in certain sense is a converse theorem), and also includes any solution to the equation, since this region is constructed when the initial condition. The disadvantage is that it has 2 points of intersection between the given edges where no one can speak of derived.

- As an attempt to overcome the above mentioned, Guidorizzi constructed a family Lyapunov functions ${ }^{13}$ which we extended ${ }^{14}$ to nonautonomous Liénard equation $\mathrm{x}^{\prime \prime}+\mathrm{f}(\mathrm{x}) \mathrm{x}^{\prime}+\mathrm{a}(\mathrm{t}) \mathrm{g}(\mathrm{x})=0$ taking as a Lyapunov function for the family

$$
V_{\alpha}(t, x, y)=\frac{1}{a(t)} W_{\alpha}(x, y)+G(x)
$$

With $G(x)=\int_{0}^{x} g(s) d s$ and $W_{\alpha}(x, y)=\int_{0}^{y-F(x)} \frac{s d s}{\alpha s+1}$ which allowed us to define $\Omega_{\alpha}$ as the following sets:

$$
\begin{gathered}
\Omega_{\alpha} \equiv \mathrm{R}^{2} \text { if } \alpha \equiv 0, \\
\Omega_{\alpha}=\left\{(\mathrm{x}, \mathrm{y}): \mathrm{y}>\mathrm{F}(\mathrm{x})-\alpha^{-1}\right\} \text { if } \alpha>0, \\
\Omega_{\alpha}=\left\{(\mathrm{x}, \mathrm{y}): \mathrm{y}<\mathrm{F}(\mathrm{x})-\alpha^{-1}\right\} \text { if } \alpha<0 .
\end{gathered}
$$

- The result obtained in the Theorem 3 is consistent with some previous results of the second author ${ }^{15}$.

\section{References}

[1] Acosta, J., L. M. Lugo, J. E. Nápoles V. and S. I. Noya (2013)-“'On some qualitative properties of a nonautonomous Liénard equation”, submitted.

[2] Guidorizzi, H. L. (1996)-“The family of functions $S_{\alpha, k}$ and the Liénard equation”, Tamkang J. of Math. 27, 37-54.

[3] Hasan, Y. Q. and L. M. Zhu (2007)-“The bounded solutions of Liénard equation", J. Applied Sciences 7(8), 1239-1240.

[4] LaSalle, J. P. (1960)-“Some Extensions of Lyapunov's Second Method", IRE Transactions on Circuit Theory, Dec, 520-527.

[5] Lugo L. M., J. E. Nápoles V. and S. I. Noya (2013)-“About a region of boundedness for some nonautonomous Lienard's Equation", Annual Meeting of the UMA, Universidad Nacional de Rosario, September 17-20 (Spanish).

[6] Lyapunov, A. M. (1949)-“Problème general de la stabilité du movement", Annals of Math. Studies, No.17, Princeton University Press, Princeton, N.J.

\footnotetext{
${ }^{13}$ Guidorizzi (1996).

${ }^{14}$ Cf. Acosta, Lugo, Nápoles and Noya (2013).

${ }^{15}$ Nápoles (2000) and Nápoles and Ruiz (1997).
} 
[7] Lyapunov, A. M. (1966)-“Stability of Motion”, Academic Press, New-York \& London, 1966.

[8] Lyapunov, A. M. (1992)-“The General Problem of the Stability of Motion", (A. T. Fuller trans.) Taylor \& Francis, London 1992.

[9] Miller, R. K. and A. N. Michel (1982)-,,Ordinary Differential Equation“, New York, Lawa Stat University.

[10] Nápoles Valdes, J. E. (2000)-“'On the boundedness and global asymptotic stability of Liénard equation with restoring term", Revista de la Unión Matemática Argentina 41(4), 47-59.
[11] Nápoles, J. E. and A. I. Ruiz (1997)-“Convergence in nonlinear systems with a forcing term", Revista de Matemática: Teoría y Aplicaciones 4(1): 1-4.

[12] Yadeta, Z. (2013)-"Lyapunov's Second Method for Estimating Region of Asymptotic Stability”, Open Science Repository Mathematics, online, doi: dx.doi.org/10.7392/Mathematics.70081944, available in http://www.open-science-repository.com/lyapunovs-secondmethod-for-estimating-region-of-asymptotic-stability.html

[13] Yoshizawa, T. (1966)-“Stability theory by Liapunov's Second Method", The Math. Soc. of Japan. 